\title{
ANALISIS KADAR DEBU TERHIRUP DAN GANGGUAN PERNAFASAN PADA TENAGA KERJA DI BAGIAN PRODUKSI SUATU INDUSTRI KAYU
}

\author{
Ineke Puspitasari, Hadi Suryono, Nur Haidah
}

\begin{abstract}
UD. Kartika Jasa is a home wood processing industry. In addition to providing product, it also creates negative impact of generating dust that in production process, the labors are at risk of exposure to dust. In an amount that exceeds TLV, dust can cause health problem for workers, one of which is respiratory disorder complaint. The purpose of this study was to determine relationship between level of inhaled dust with respiratory disorders complaint.

This research is Cross Sectional analytical research with 20 workers as samples. Method af data collection was carried out by observation of inhaled dust. Data analysis used Fisher's exact test.

From the result of inhaled dust level measurement, it is found out that most of the labor force were not eligible (55.0\%) with severe respiratory disorders complaint (70.0\%). Most of the labor force aged > 30 years $(60.0 \%)$, length of labor $<10$ years $(55.0 \%)$, had smoking habit $(75.0 \%)$ did not have habit of wearing PPE at all (65.0\%). In inhaled dust level variable, age, years of smoking habit and the habit of wearing PPE affected respiratory disorder complaint experienced by workforce with $\rho<0,05$.

The research concludes that there was a relationship between the level of inhaled dust and respiratory disorder complaint on labor. Effort to control technically, administratively, and the use of PPE in the workplace is required.
\end{abstract}

Keywords : Dust Concetration, respiratory disorders

\section{PENDAHULUAN}

Udara merupakan zat yang paling penting setelah air dalam memberikan kehidupan di permukaan bumi ini. Pesatnya perkembangan dan kemajuan pembangunan di bidang industry mengakibatkan banyaknya berbagai pabrik yang beroprasi seperti kimia, semen, kayu, pembangkit listrik maupun yang lainnya. Kegiatan industri tersebut berpotensi dalam menghasilkan bahan pencemar di udara, salah satunya adalah debu. Debu adalah partikel padat yang dapat dihasilkan oleh manusia atau alam dan merupakan hasil dari proses pemecahan suatu bahan (Mukono, 2003: 8).

Pemaparan debu dalam proses produksi tidak hanya mengganggu aspek keindahan dan kebersihan saja, namun dalam jangka waktu yang lama akan memberikan dampak negatif bagi kesehatan manusia baik pekerja maupun masyarakat sekitar produksi apabila tidak ditangani secara tuntas. Pengendalian yang tidak dilakukan dengan maksimal akan meningkatkan pencemaran di udara. Debu dapat menyebabkan gangguan pada saluran pernafasan (Mukono, 2003: 12-23).

Berdasarkan penelitian Sholikhah (2014) menyatakan bahwa hasil pengukuran kadar debu total pada industri kayu menunjukkan adanya hubungan bermakna antara kadar debu dengan keluhan gangguan pernafasan yang dialami oleh pekerja. Sedangkan menurut penelitian Sari Sri Sakti Aji (2010) di kecamatan Karanganyar Kabupaten Karanganyar menyatakan bahwa ada hubungan yang signifikan antara paparan debu dengan kapasitas fungsi paru pekerja, yakni sebesar $63,3 \%$ kapasitas fungsi paru pekerja tidak normal.

UD. Kartika Jasa berlokasi di Kecamatan Gunung Anyar Surabaya dengan jumlah tenaga kerja di bagian produksi sebanyak 21 orang, merupakan home industri memproduksi kerajinan kayu berupa pintu, kusen, jendela, serta lemari, sehingga dalam menghasilkan produk menimbulkan dampak negatif dari proses produksi yaitu menghasilkan debu yang yang dapat mengganggu kenyamanan maupun kesehatan tenaga kerja.

Berdasarkan hasil observasi diketahui bahwa secara kasat mata debu di bagian produksi sangat pekat dilihat dari partikel hasil olahan kayu yang ada di udara, dan dari hasil wawancara awal yang telah dilakukan dengan 12 pekerja, 8 (66,67\%) pekerja mengeluh mengalami gangguan pernafasan antara lain bersin, sesak nafas, batuk, dan hidung tersumbat.

Penelitian ini bertujuan untuk mengetahui hubungan kadar debu terhirup dengan keluhan gangguan saluran pernafasan pada tenaga kerja bagian produksi UD Kartika Jasa.

\section{METODE PENELITIAN}

Jenis penelitian ini termasuk penelitian analitik dengan pendekatan secara Cross Sectional. Populasi dalam penelitian ini adalah seluruh tenaga kerja di bagian produksi. Besar sampel adalah 20 orang dari 21 tenaga kerja.

Metode pengumpulan data dalam penelitian ini adalah observasi dengan menggunakan lembar observasi, wawancara 
dengan menggunakan lembar kuesioner dan pengukuran kadar debu terhirup dengan menggunakan Personal Dust Sampler(PDS). Analisis data menggunakan Uji exact fisher's.

\section{HASIL PENELITIAN DAN PEMBAHASAN}

Analisis Hubungan Kadar Debu
Dengan Kerhirup
Pernafasan Tenaga Kerja

Tabel 1

Hubungan Kadar Debu Terhirup Dengan Keluhan Gangguan Saluran Pernafasan Tenaga Kerja Di Bagian Produksi Kayu UD. Kartika Jasa Kec.Gunung Anyar Surabaya Tahun 2016

\begin{tabular}{cccc}
\hline \multirow{2}{*}{ No. } & \multirow{2}{*}{ Kadar Debu Terhirup } & \multicolumn{2}{c}{ Jenis Keluhan Gangguan Saluran Pernafasan } \\
\cline { 3 - 4 } & \multirow{2}{*}{ Tidak Memenuhi Syarat } & 1 & Berat \\
\hline 2. & \multirow{2}{*}{ Memenuhi Syarat } & $(16,7 \%)$ & $(71,4 \%)$ \\
\hline \multirow{2}{*}{ Jumlah } & 5 & 4 \\
& & $(83,3 \%)$ & $(28,6 \%)$ \\
\hline
\end{tabular}

Berdasarkan tabel 1 sebagaian besar kadar debu terhirup tidak memenuhi syarat $\left(\leq 5 \mathrm{mg} / \mathrm{m}^{3}\right.$ udara) dengan keluhan gangguan saluran pernafasan berat sebanyak 10 orang dari 11 pekerja. Dari hasil uji Exact Fisher didapatkan hasil bahwa ada hubungan antara kadar debu terhirup dengan keluhan gangguan saluran pernafasan tenaga kerja $(P=0,038<a)$. Hal tersebut dikarenakankadar debu yang dihirup tenaga kerja melebihi NAB.Menurut Peraturan Menteri Tenaga

\section{Hubungan Umur Dengan Keluhan Gangguan Saluran Pernafasan}

Tabel 2

Hubungan Umur Dengan Keluhan Gangguan Saluran Pernafasan Tenaga Kerja Di Bagian Produksi Kayu UD. Kartika Jasa Kec. Gunung Anyar Surabaya Tahun 2016

\begin{tabular}{cccc}
\hline \multirow{2}{*}{ No. } & \multirow{2}{*}{ Umur } & \multicolumn{2}{c}{ Jenis Keluhan Gangguan Saluran Pernafasan } \\
\cline { 3 - 4 } 1. & $\leq 30$ tahun & 5 & Berat \\
\hline 2. & $>30$ tahun & $(83,3 \%)$ & 3 \\
& \multirow{2}{*}{ Jumlah } & $(16,7 \%)$ & $11 \%)$ \\
\hline & 6 & $(78,6 \%)$ \\
\hline
\end{tabular}

Berdasarkan tabel 2 sebagian besar berumur $>30$ tahun dengan keluhan gangguan saluran pernafasan berat sebanyak 11 orang dari 12 tenaga kerja. Dari hasil uji Exact Fisher didapatkan hasil bahwa ada hubungan antara umur dengan keluhan gangguan saluran pernafasan tenaga kerja $(\mathrm{P}=0,018<\mathrm{a})$. Hal ini disebabkan karena semakin tua seseorang akan semakin rentan
Kerja dan Transmigrasi Nomor PER.13/MEN/X/2011 Tentang Nilai Ambang Batas Faktor Fisika dan Faktor Kimia Di Tempat Kerja. Nilai Ambang Batas (NAB) untuk debu kayu yang dapat dihirup adalah 5 $\mathrm{mg} / \mathrm{m}^{3}$ udara. Dimana kadar debu yang dihirup juga sangat mempengaruhi keluhan yang dialami oleh tenaga kerja. Pemaparan debu kayu yang semakin lama dapat menimbulkan berbagai penyakit kerja akibat debu kayu, contohnya asma. terhadap paparan debu. Sifat elastisitas paru-paru tidak berubah pada usia 7-39 Tahun, tetapi ada kecenderungan menurun pada usia 25 Tahun, dan penurunan ini semakin terlihat nyata setelah usia 30 Tahun, sehingga kekuatan bernafas menjadi menurun akibatnya volume udara pada saat bernafas akan menjadi lebih sedikit (Wibowo,D, 2005). 
Tabel 3

Hubungan Masa Kerja Dengan Keluhan Gangguan Salura Pernafasan Tenaga Kerja Di Bagian Produksi Kayu UD. Kartika Jasa Kec. Gunung Anyar SurabayaTahun 2016

\begin{tabular}{cccc}
\hline \multirow{2}{*}{ No. } & \multirow{2}{*}{ Masa Kerja } & \multicolumn{2}{c}{ Jenis Keluhan Gangguan Saluran Pernafasan } \\
\cline { 3 - 4 } & \multirow{2}{*}{10 tahun } & 6 & Berat \\
\hline 2. & $(100 \%)$ & 5 \\
& $>10$ tahun & 0 & $(35,7 \%)$ \\
\hline \multirow{2}{*}{ Jumlah } & $(0 \%)$ & $(64,3 \%)$ \\
& & 6 & 14 \\
& $(100 \%)$ & $(100 \%)$ \\
\hline
\end{tabular}

Berdasarkan tabel 3 sebagaian besar bekerja $\leq 10$ tahun dengan keluhan gangguan saluran pernafasan ringan sebanyak 6 orang dari 11 tenaga kerja. Dari hasil uji Exact Fisher didapatkan hasil bahwa ada hubungan antara masa kerja dengan keluhan gangguan saluran pernafasan tenaga kerja $(P=0,012<a)$.

Hal ini disebabkan karena masa kerja lebih dari 10 Tahun dalam bekerja, mengakibatkan semakin tinggi resiko terjadinya gangguan paru pada tenaga kerja industri yang berdebu (Yulaekah, 2007).

\section{Hubungan Kebiasaan Merokok Dengan Keluhan Gangguan Saluran Pernafasan}

\section{Tabel 4}

Hubungan Kebiasaan Merokok Dengan Keluhan Gangguan Saluran Pernafasan Tenaga Kerja Di Bagian Produksi Kayu UD. Kartika Jasa Kec. Gunung Anyar Surabaya Tahun 2016

\begin{tabular}{cccc}
\hline \multirow{2}{*}{ No. } & \multirow{2}{*}{ Kebiasaan Merokok } & \multicolumn{2}{c}{ Jenis Keluhan Gangguan Saluran Pernafasan } \\
\cline { 3 - 4 } & & 2 & Bingan \\
& \multirow{2}{*}{ Merokok } & $(33,3 \%)$ & $(92,9 \%)$ \\
\hline 2. & Tidak Merokok & $(66,7 \%)$ & 13 \\
& \multirow{2}{*}{ Jumlah } & 6 & $(7,1 \%)$ \\
\hline
\end{tabular}

Berdasarkan tabel 5 sebagaian besar memiliki kebiasaan merokok dengan keluhan gangguan saluran pernafasan berat sebanyak 13 orang dari 15 tenaga kerja. Dari hasil uji Exact Fisher didapatkan hasil $\mathrm{P}=0,014<\mathrm{a}$, yang berarti

\section{Hubungan Kebiasaan Memakai APD Dengan Keluhan Gangguan Saluran Pernafasan}

Tabel 5

Hubungan Kebiasaan Memakai Apd Dengan Keluhan Gangguan Saluran Pernafasan Tenaga Kerja di Bagian Produksi Kayu UD. Kartika Jasa Kec.Gunung Anyar Surabaya tahun 2016

\begin{tabular}{cccc}
\hline \multirow{2}{*}{ No. } & \multirow{2}{*}{ Kebiasaan Memakai APD } & \multicolumn{2}{c}{ Jenis Keluhan Gangguan Saluran Pernafasan } \\
\cline { 3 - 4 } & & 1 & Berat \\
& \multirow{2}{*}{ Tidak Rutin Memakai } & $(16,7 \%)$ & 12 \\
& & 5 & $(85,7 \%)$ \\
\hline 2. & Selalu Memakai & $(83,3 \%)$ & $(14,3 \%)$ \\
& \multirow{2}{*}{ Jumlah } & 6 & 14 \\
& & $(100 \%)$ & $(100 \%)$ \\
\hline
\end{tabular}

Berdasarkan tabel 5 sebagian besar tidak rutin memakai APD dengan keluhan gangguan saluran pernafasan berat sebanyak 12 orang dari 13 tenaga kerja. Dari hasil uji Exact Fisher didapatkan hasil nilai $\mathrm{P}=0,007<\mathrm{a}$ yang berarti bahwa ada bahwa ada hubungan antara kebiasaan merokok dengan keluhan gangguan saluran pernafasan tenaga kerja. Karena merokok dapat menyebabkan perubahan struktur, fungsi saluran napas dan jaringan paru-paru dengan segala macam gejala klinisnya (S. Yulaekah, 2007).

hubungan antara kebiasaan memakai APD dengan keluhan gangguan saluran pernafasan tenaga kerja. Karena kebiasaan memakai APD akan mengurangi pemaparan debu dalam paru-paru, karena alat ini berfungsi sebagai penyaring udara pernafasan, sehingga kelainan paru-paru dapat dihambat. 


\section{KESIMPULAN}

1. Kadar debu terhirup pada tenaga kerja yang tidak memenuhi syarat sebesar 55\%, sehingga prosentase tenaga kerja yang mengalami keluhan gangguan saluran pernafasan berat sebesar $70 \%$.

2. Tenaga Kerja sebagian besar berumur $>30$ tahun, dengan masa kerja < 10 tahun, sebagian besar tenaga kerja berjenis kelamin laki-laki sehingga memiliki kebiasaan merokok sebesar $75 \%$, serta tidak memiliki kebiasaan memakai APD saat bekerja

3. Ada hubungan kadar debu terhirup dan karakteristik tenaga kerja meliputi umur, masa kerja, kebiasaan merokok, dan kebiasaan memakai APD dengan keluhan gangguan saluran pernafasan pada tenaga kerja.

4. Pengukuran iklim kerja di ruang produksi adalah suhu $33^{\circ} \mathrm{C}$, kelembaban $71 \%$, dan kecepatan aliran udara $0,86 \mathrm{~m} / \mathrm{s}$.

\section{DAFTAR PUSTAKA}

Aji, S. S., 2010. Hubungan Paparan Debu Dengan Kapasitas Fungsi Paru Pekerja Penggilingan Padi di Kecamatan Karanganyar Kabupaten Karanganyar. Skripsi. Fakultas Kedokteran Universitas Sebelas Maret Surakarta.

Anizar, 2009. Teknik Keselamatan dan Kesehatan Kerja di Industri. Yogyakarta, Graha IImu: 123.

Azwar, Azrul, 1995. Pengantar IImu Kesehatan Lingkungan. Jakarta, PT. Mutiara Sumber Widya: 172.

Bohadana, A.B.2000. Symptoms Airway Responsiveness, and Exposure to Dust in Beach and Oak Wood Workers Occup Environ Med.

Budijanto, Didik, dkk. 2005. Metodologi Penelitian. Surabaya, Unit Penelitian Dan Pengabdian Masyarakat Politeknik Kesehatan Surabaya: 22-47

Bustan, M,Najib.2015. Manajemen Pengendalian Penyakit Tidak Menular. Jakarta, PT Rineka Cipta: 269

Chandra, Budiman, 2006. Pengantar Kesehatan Lingkungan. Jakarta, EGC: 75.

Dhaise, Abu.1997. Pulmonary Manifestation in Cement Workers in Jordan, Ibird, Int Jour Occup Med Environ Health.

Fitria, L. 2008. Kualitas Udara dalam Ruang Perpustakaan Universitas $X$ Ditinjau dari Kualitas Biologi, Fisik, dan Kimiawi. Makara Seri Kesehatan

Hasanah, Laylatul, 2012. Pengaruh Kadar Debu Kayu Terhadap Keluhan Subyektif (Studi Kasus pada Tenaga Kerja Meubel Industri Rumah Tangga (home industry) di Dusun Blajud Desa Karduluk Kecamatan Pragaan Kabupaten Sumenep). KTI. Jurusan

\section{SARAN}

1. Bagi UD. Kartika Jasa

Penambahan ventilasi pada ruang produksi bagian belakang, agar hamburan debu yang dihasilkan berkurang, menyediakan air bagi tenaga kerja, dilakukan pemantauan lingkungan secara rutin, menyediakan alat pelindung diri bagi tenaga kerja dan pengawasan pemakaiannya, serta perlu adanya pemasangan pamflet peringatan bahaya kerja dan kecelakaan akibat kerja serta larangan merokok di tempat kerja

2. Bagi Tenaga Kerja

Sebaiknya selalu menggunakan APD selama bekerja, serta mengurangi kebiasaan merokok saat bekerja
Kesehatan Lingkungan Poltekkes Kemenkes Surabaya: 3

Hastono, P.S., 2013. Statistik Kesehatan. Jakarta, PT Raja Grafindo Persada: 6-99

Hendrawati, W.I., Pruhartono,J., Yunus,F., 1998. Pengaruh Debu Kayu terhadap Paru dan Faktor-faktor Resikonya di Kalangan Pekerja Industri Permebelan Kayu PT. X di Bogor. Journal Respir Indo.

Herlinda, C. W., 2011. Hubungan Kadar Debu Dengan Keluhan Subyektif (Studi Pada Tenaga Kerja Unit Produksi di PT. Japfa Comfeed Indonesia, Tbk). KTI. Jurusan Kesehatan Lingkungan Poltekkes Kemenkes Surabaya: 6-14

Hosiah, 2005. Studi Tentang Upaya Pengendalian Debu Kayu di Ruang Produksi CV. Jamrud Sidoarjo. KTI. Jurusan Kesehatan Lingkungan Poltekkes Kemenkes Surabaya: 15-16

Keputusan Menteri Kesehatan No..1405/MENKES/ SK/XI/ 2002 tentang Persyaratan Kesehatan Lingkungan Kerja Perkantoran dan Industri,

Khairah, 2012, Analisis Konsentrasi Debu dan Keluhan Kesehatan pada Masyarakat di Sekitar Pabrik Semen di Desa Kuala Indah Kecamatan Seisuka Kabupaten Batu Bara.

Meta, Suryani. 2005. Analisis Faktor Resiko Paparan Debu Kayu Terhadap Gangguan Fungsi Paru Pada Pekerja Industri Pengolahan Kayu PT. Surya Sindoro Sumbing Wood industri Wonosobo. Jurnal Kesehatan Lingkungan Indones.

Mufidah, Selga., 2015. Hubungan Kadar Debu Yang Terhirup dengan Keluhan Subyektif pada Tenaga Kerja di Bagian Penggergajian Batu Kumbung (Studi Di UD. Sri Rejeki 
Desa Leran Kulon Kecamatan Palang Kabupaten Tuban. KTI. Jurusan Kesehatan Lingkungan Poltekkes Kemenkes Surabaya: 14

Mukono, H. J, 2003. Pencemaran Udara dan Pengaruhnya Terhadap Gangguan Saluran Pernapasan. Surabaya, Airlangga University Press: 8-23.

Notoatmodjo, Soekidjo, 2005. Metode Penelitian Kesehatan. Jakarta, PT. Rineka Cipta: 70102.

Peraturan Menteri Tenaga Kerja dan Transmigrasi Nomor 08 Tahun 2010 Lampiran Tentang Alat Pelindung Diri.

Peraturan Menteri Tenaga Kerja dan Transmigrasi Nomor 13 Tahun 2011 TentangNilai Ambang Batas Faktor Fisika dan Faktor Kimia Di Tempat Kerja.

Rahayu, Leni, 2005. Studi Pencemaran Debu Udara Ambien Dan Prevalensi Penyakit Saluran Pernafasan di Surabaya Pusat (Wilayah Puskesmas Kedungdoro Tahun 2005). KTI. Jurusan Kesehatan Lingkungan Poltekkes Kemenkes Surabaya: 12

Rochmawati, Yuni, 2006. Upaya Pengendalian Debu Kayu (Studi Pada Bagian Produksi PT. Dharma Satya Nusantara Surabaya Tahun 2006).KTI. Jurusan Kesehatan Lingkungan Poltekkes Kemenkes Surabaya: 9-10

Salisa, S. S. 2011. Paparan Asap dari Aktivitas Pengasapan Ikan terhadap Keluhan Mata, Pernafasan, dan Fungsi Paru (Studi di Jalan Kejawan Lor Kelurahan Kenjeran, Kecamatan Bulak, Surabaya). Skripsi. Fakultas Kesehatan Masyarakat. Universitas Airlangga.
Sholikhah, Anindya.,2014. Kadar Debu Total Pabrik Kayu dan Hubungannya Dengan Keluhan Pernafasan Pada Pekerja di PT.X. Skripsi. Universitas Airlangga Surabaya.

Somantri, Irman, 2009. Asuhan Keperawatan Pada Klien Dengan Gangguan Sistem Pernafasan. Jakarta, Salemba Medika: 5051.

Suma'mur,dkk 1985. Penyakit-penyakit akibat kerja. Jakarta, Grafindo Utama: 31.

Suma'mur, 2013. Higiene Perusahaan Dan Kesehatan Kerja (Hiperkes). Jakarta, Sagung Seto. Edisi Kedua: 154-275.

Suma'mur, 1984. Higiene Perusahaan Dan Kesehatan Kerja. Jakarta, Gunung Agung: 85-126.

Triatmo, W.,Adi, M.S., \& Hanani,Y.2006. Paparan Debu Kayu dan Gangguan Fungsi Paru pada Pekerja Mebel (Studi di PT. Alis Jaya Ciptatama). Jurnal Kesehatan Lingkungan Indonesia, Diakses dari http://ejournal.undip.ac.id/index.php/jkli/a rticle/download/312/114 (28 Juli 2016)

Wibowo,D. K., 2005. Studi Tentang Kadar Debu dan Keluhan Subyektif Pada Tenaga Kerja Di Pabrik Penggergajian Batu Kumbung Di Leran Tuban. KTI. Jurusan Kesehatan Lingkungan Poltekkes Kemenkes Surabaya: 9-16

Yulaekah, S., 2007. Paparan Debu Terhirup dan Gangguan Fungsi Paru Pada Pekerja Industri Batu Kapur (Studi Di Desa Mrisi Kecamatan Tanggung harjo Kabupaten Grobogan). Tesis. Konsentrasi Kesehatan Lingkungan Industri Universitas Diponegoro Semarang. 